\section{VIVER DE PÔQUER: COMO O JOGO PROFIssIONAL AUUDA A ENTENDER A EXPOSIÇÃO DE SI E O TRABALHO NÁO REMUNERADO NAS REDES SOGIAIS}

\author{
Rafael Evangelista
}

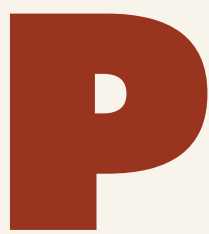

oderiam os ambientes das redes sociais da internet - que em suas características aditivas (1) unem diversão/brincadeira/jogo - serem comparados aos sistemas de pôquer online? Por um lado, ambos funcionam como entretenimento, divertem, prendem a atenção e "fazem o tempo passar" para milhōes de usuários diariamente. Ao mesmo tempo, são um ambiente de trabalho, muitas vezes fora da relação salarial, para milhares de pessoas - milhōes, no caso das redes sociais. As redes são usadas para expor as mais variadas produções intelectuais, de sujeitos que tentam atrair atenção para si, como escritor, músico, poeta, intelectual, comediante, comunicador, fotógrafo, ou para links externos que hospedem essas obras. Os sites de pôquer são a arena em que acontece a performance de milhares de jogadores de pôquer profissionais, vigiada e verificada por dispositivos de registro, que atravessam os dias participando de mesas de cartas, por vezes várias simultaneamente, com objetivo de, ao menos, obterem ganhos mínimos. Nas suas redes específicas, ou nas redes sociais gerais, os números que mostram o bom desempenho serão usados para conseguirem contratos e patrocínios, que podem levá-los a um estágio mais confortável na carreira.

Este relato preliminar de pesquisa, que usa de entrevistas semiestruturadas, observação de campo, revisão bibliográfica e análise de publicaçôes, pretende, a partir do exame da figura, do cotidiano e das ideias dos jogadores autoreferidos como profissionais, indagar sobre as relações entre jogo, diversão, trabalho e profissionalização nas redes sociais. Mais do que um ambiente de conversação entre pessoas, elas ganharam centralidade enquanto nó de relaçóes comerciais e de valorização simbólica e informacional, de pessoas e produtos, na sociedade contemporânea. Operam a partir de registros permanentes de todas as trocas informacionais. A extração de valor dessas informaçôes se dá por meio de sofisticados mecanismos de vigilância e análise dos dados produzidos, que funcionam como o combustível a alimentar análises comportamentais úteis, entre outros, ao mercado publicitário.

PROFISSIONALIZAÇÃO EM UM JOGO DE HABILIDADE O número de jogadores de pôquer, online e offline, vem crescendo ao longo dos anos (2). Estimativas da indústria do pôquer online afirmam que, em 2014, esse foi um negócio de 2 bilhōes de euros (3). Ainda segundo a própria indústria, entre os fatores principais que têm contribuído para o crescimento estão: a expansão da infraestrutura de banda larga; inovação tecnológica do setor da tecnologia da informação; aumento no uso de tablets e smartphones; investimentos da indústria de jogos; e confiança dos jogadores nos mecanismos de pagamentos online. Informes da indústria ressaltam ainda que, desse público crescente, destacam-se dois perfis: os apostadores offline, que passaram a ganhar confiança nas plataformas online; e jovens aficionados por videogames e jogos eletrônicos online em geral, que estariam sendo conquistados pelo mundo do pôquer.

É fato que o pôquer passou a receber grandes investimentos da indústria em sua promoção. Programas esportivos de televisão são intermediados por anúncios de sites de jogo online; torneios de pôquer ao redor do mundo recebem extensiva cobertura televisiva; astros do futebol (Ronaldo, Cristiano Ronaldo, Neymar) e do tênis (Boris Becker, Rafael Nadal) são contratados como garotos propaganda e se envolvem em competiçôes promocionais; atores como Ben Affleck, Meg Tilly e Tobey Maguire são conhecidos jogadores e reality shows figurando atores se tornaram populares; revistas especializadas promovem torneios, cultuam jogadores habilidosos e dão dicas de como profissionalizar-se.

O mundo do pôquer online não se reduz aos sites que hospedam os jogos. Ele se constitui como um sistema em que se relacionam os já mencionados sites; fóruns de discussão na internet utilizados pelos jogadores; publicaçôes profissionais online e offline; programas de televisão; blogs e perfis de redes sociais mantidos por jogadores, contendo dicas, estratégias de jogo, relatos sobre performance, estatísticas pessoais e participações em torneios; empresas de cartão de crédito localizadas em paraísos fiscais; e empresas que trocam créditos virtuais por moeda corrente.

Celebridade, visibilidade, notoriedade e promoção de si são fundamentais para as ideias que desenvolvemos aqui. Ao mesmo tempo que a popularização do jogo e o incentivo à profissionalização passam por promover a percepção de que mesmo pessoas ditas comuns, ainda que célebres em outros campos de atuação, são capazes de conseguirem bons ganhos com o jogo, obter sucesso em uma tentativa de profissionalização passa quase que necessariamente por ser socialmente reconhecido e notabilizar-se como um jogador hábil capaz de auferir altos ganhos. Nisso os sites satélites aos ambientes onde o jogo realmente acontece são importantes.

Tornar-se um profissional do pôquer significa fazer dele sua principal ou única fonte de renda, dedicando ao jogo, online e offline, significativa parte do dia de trabalho. McCormack \& Griffiths (2) procuraram entender, em estudo, as diferenças entre os jogadores recreativos e profissionais. Para isso, entrevistaram nove jogadores, sendo três autointitulados profissionais, um semiprofissional e cinco recreativos, todos ingleses. Algumas de suas observaçōes vão na mesma direção dos achados deste trabalho.

$\mathrm{O}$ jogador profissional trata o pôquer como um trabalho, o que implica uma determinada assiduidade e postura com relação ao jogo. Em geral, esses jogadores repetem uma frequência (de 5 a 6 dias por semana) e uma quantidade mínima de horas por dia. No artigo 
"Playing poker for a living" (4), publicado em um site dedicado a jogadores frequentes (5), a rotina é descrita da seguinte forma: "Eu acordo cedo, como meu café da manhã e tomo um banho antes de ir para as mesas. ( ) Eu tipicamente jogo pôquer por três ou quatro horas de manhã e então vou fazer algo para almoçar. Na tarde, eu procuro fazer alguma outra coisa ( ). À noite inicio outra sessão, para encontrar os jogadores amadores do fim do dia”. Ele então descreve jogar até o limite em que identifica não estar mais alerta o suficiente.

Esse é um comportamento que também é registrado por McCormack \& Griffiths (2) e que igualmente encontramos descrito em nossas entrevistas: no mínimo oito horas por dia, chegando a 12 ou 14 em alguns momentos. Com o diferencial de que, por serem jogadores brasileiros, em outro fuso horário, os períodos não são necessariamente os mesmos. Há uma busca pelo fim do dia nos países centrais, "quando o gringo volta meio bêbado do bar", quando os adversários amadores estão mais fragilizados. Aparece aqui, ainda, a diferença cambial, de custo de vida e de ganhos nos países mais desenvolvidos. O dinheiro que o trabalhador comum em um país mais rico pode desperdiçar em jogos se torna o ganho diário no país mais pobre. As diferenças entre Sul e Norte, entre países pobres e países ricos, não desaparecem no pano verde das mesas de jogos. O que é dinheiro miúdo, a ser desperdiçado em um hemisfério pode virar o lucro cotidiano em outro.

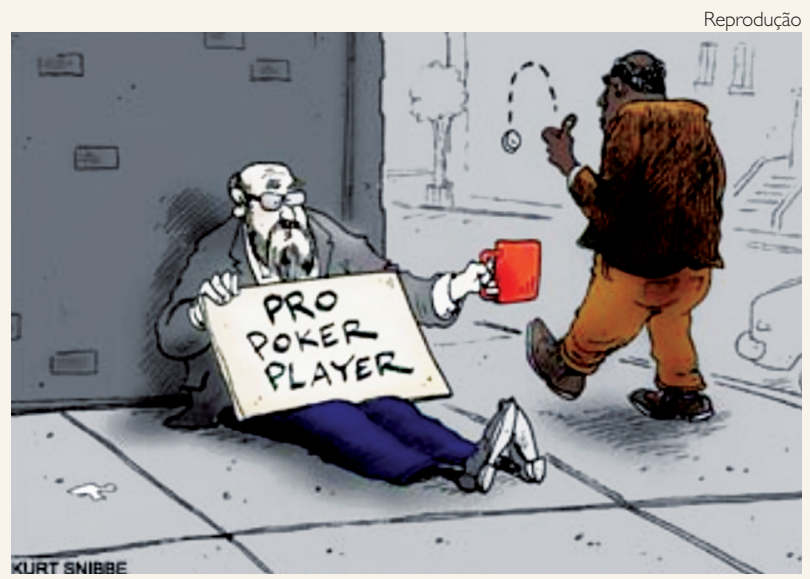

Imagem compartilhada em sites de profissionais que ilustra a situação financeira difícil de boa parte dos jogadores

Os entrevistados de McCormack \& Griffiths relatam ganhos anuais de US\$150 mil para os jogadores profissionais e US\$30 mil para o entrevistado semiprofissional. São números muito distantes dos descritos em sites brasileiros que dão dicas para que um amador se torne um profissional. É bastante difícil chegar a um número concreto, já que a maioria das histórias gira em torno de nomes já famosos e vitoriosos. Estes, em início de carreira, quando estariam ganhando mais experiência ganhariam de US\$ 2 mil a US\$ 6 mil (6). No entanto, como padrão mínimo para um jogador iniciante fala-se em R \$ 1 mil mensais. "Precisar de mil reais por mês não é problema, o que não dá é pra querer ter um padrão de vida alto ou sustentar uma família sem saber onde está pisando" (7).

Uma constante nesses textos de dicas para a profissionalização são as comparaçōes entre a administração da carreira de jogador e o gerenciamento de um fundo de ações ou de aplicações em mercado financeiro. Por um lado, fala-se em investimento, em estar preparado para períodos longos, de até dois anos, amealhando prejuízo enquanto se adquire experiência e conhecimento. Por outro, em correr riscos e enfrentar prejuízos mas também vislumbrar a possibilidade de ganhos extraordinários. "Mas isso não é exclusivo do pôquer. Quem trabalha com mercado financeiro ou bolsa de valores, por exemplo, está sujeito aos mesmos riscos. A boa administração de seu capital na bolsa equivale ao que um profissional deve fazer de seu bankroll. Administrar envolve ter registros acurados, planejar os investimentos, as retiradas mensais etc", diz um deles (8). McCormack \& Griffiths registram fala parecida: "Quer dizer, eu vejo como bancos de investimento, eles investem dinheiro e eles estão basicamente apostando todos os dias se as ações vão subir ou descer e num dia específico eles não sabem o que vai acontecer, mas a longo prazo a habilidade deles busca prever o que vai acontecer para fazê-los ganhar dinheiro".

O longo prazo também aparece como maneira para driblar o azar, vencer a variância. Além de jogarem por longos períodos de tempo os profissionais jogam muitas mesas simultaneamente, de alguma maneira aumentando sua "produtividade". Busca-se diminuir o risco pelo excesso, pela repetição, os momentos de azar são compensados pela possibilidade de uma melhor sorte na mão seguinte. Quanto mais experiente o jogador mais capaz ele se torna de atuar em várias mesas ao mesmo tempo, bastando uma olhadela nas cartas para que se tome a decisão necessária. Os relatos são de até dez mesas sendo jogadas ao mesmo tempo pelo mesmo profissional.

Isso também é possível pois estilo de jogo desenvolvido não requer intensidade. $\mathrm{O}$ jogador profissional evita correr riscos que os inexperientes, os cansados e os bêbados podem correr. O profissional deve se distanciar emocionalmente do jogo, aceitar as perdas como normais, não buscando compensá-las imediatamente e evitar ao máximo o risco. A busca pelo lucro no dia a dia não vem de grandes ganhos e ocasiōes, mas de pequenas e repetidas vitórias em muitas mesas ao longo do dia de trabalho. Isso aparece também nas recomendações de que é preciso estar relaxado e de cabeça fresca para se jogar bem. O jogador estressado "tilta” (como as máquinas de pinball entravam em tilt) e não toma decisões racionais. Do mesmo modo, o jogador em dificuldades financeiras costuma jogar mal, pois está pressionado.

A AUTOMATIZAÇÃO Profissionais e amadores - menos frequentemente - têm se utilizado de outros softwares como auxiliares nesse estilo de jogo mecânico, racional. Um tipo desses programas faz cálculos matemáticos das cartas na mesa, apresentando as chances de vitória de cada jogador. Esse tipo de estimativa é uma constante nos jogos offline televisionados. Acompanha-se a oscilação desse número ao longo do jogo para cada um dos jogadores, criando-se tensão 
e suspense. O jogador profissional, ainda que não possa ler as mãos dos oponentes como na televisão, usa os números para diminuir as chances de perdas. Consegue, assim, calcular quando agir de maneira mais conservadora ou agressiva com menos riscos.

Outra modalidade de software auxiliar são os que "leem" as estatísticas de outros jogadores, para que se possa entender o estilo do oponente e melhor jogar contra ele. Como é preciso um registro fixo, um nome de usuário constante para se fazer os saques em moeda corrente, os jogadores costumam ter somente um nome de usuário. Isso permite o ranqueamento e o acompanhamento dessas identidades. A partir dos nomes de usuário extrai-se um perfil de jogo, útil para se saber contra que estilo de jogo e nível de jogador se está competindo. Jovens acostumados com videogames notadamente manuseiam mais facilmente esses programas, que envolvem a habilidade de controlar várias aplicações diferentes ao mesmo tempo.

Uma das dificuldades apontadas pelos profissionais tem sido lidar com robôs, bots, adversários não humanos totalmente automatizados utilizados por terceiros, como os reportados pelo jornal The New York Times, que registra um avanço recente na qualidade desses programas (9). Há, inclusive, um mercado que vende esses robôs, desenvolvidos para serem usados em sites específicos, podendo ainda serem adaptados pelo comprador com variaçóes no estilo de jogo. Ao dono malicioso desses robôs cabe encontrar ou desenvolver falsos perfis hospedeiros, perfis que possam sacar o dinheiro ganho, já que a retirada de valores costuma ser um processo burocraticamente complicado.

O combate aos robôs é feito mais eficazmente pelos maiores sites e redes de jogo online. Além de melhores mecanismos tecnológicos de detecção, esses sites têm um processo mais complicado de retirada de valores e de verificação da identidade real dos perfis utilizados. Os sites de menor prestígio são mais vulneráveis e também lenientes aos robôs. No entanto, oferecem mais bônus e cobram menos taxas dos jogadores.

A reclamação contra os robôs, especialmente por parte dos profissionais, ainda que justa, tem um algo de irônico. $\mathrm{O}$ estilo de jogo "robótico" é justamente uma das características desses jogadores e os mais jovens são apontados como mais hábeis exatamente por melhor se utilizarem de softwares auxiliares, por melhor se hibridarem com as novas tecnologias de jogo online.

Ainda nesse sentido, pode-se apontar como o uso de robôs no pôquer guarda relaçôes com trabalhadores braçais sendo substituídos nas linhas de montagem por máquinas. Outro fenômeno, mais recente, tem sido a ameaça vivida por profissões vistas como mais intelectualizadas, como o jornalismo, de substituição por algoritmos escritores de notícias. A prática profissional primeiro é robotizada via processos de trabalho - e de escrita - muito normatizados e regulados. Depois substitui-se esse profissional por autênticos robôs.
OS AMBIENTES DE TROCAS DE INFORMAÇÕES Como dito acima, uma das dificuldades dos profissionais do pôquer está no recebimento do dinheiro ganho, o chamado cashout. Esteé, inclusive, um fator para a escolha do site a se jogar (10). Trata-se de um processo que, a depender do site, pode ser demorado (às vezes meses), complicado e, como envolve transferências internacionais, bastante custoso devido a taxas bancárias e impostos. Geralmente evita-se receber por vias tradicionais, sendo possível duas alternativas, ou conta internacional em paraísos fiscais ou um mercado paralelo de créditos, amador ou profissional.

As contas internacionais servem bem para ganhos médios e para gastos cotidianos. São serviços prestados pelos bancos mirando também esse público de apostadores (no caso não somente em pôquer, mas em cassinos e competiçôes esportivas). Pede-se ao site a conversão dos créditos para moeda real e o dinheiro é depositado em uma conta internacional. O cliente recebe, em seu país, um cartão de crédito comum, com o qual consegue fazer saques na moeda do país e compras em lojas que aceitam cartões de crédito internacionais. $\mathrm{O}$ banco ganha cobrando taxas nas operações de retirada.

Já o mercado de créditos acontece principalmente em fóruns de discussão. Tem a vantagem de ser rápido e direto, com os créditos sendo transferidos instantaneamente e o dinheiro sendo trocado informalmente entre contas bancárias no país. Taxas de câmbio, tarifas e descontos são negociados entre compradores e vendedores, num mercado que envolve não somente os jogadores, mas intermediários que lucram com essas transações.

Redes sociais, sites de informação, blogs de jogadores e fóruns de discussão são parte importante do mundo do jogo profissional. Os sites de jogos costumam variar a porcentagem que cobram do jogador (o chamado rake), os bônus oferecidos por dinheiro inserido e os descontos para aqueles que passam muito tempo jogando (o rakeback). Informações atualizadas sobre essas oportunidades são importantes, o rakeback é um dos mecanismos de fidelização e atração de jogadores mais significativo.

Além disso, os jogadores costumam repetir que o aprendizado nunca acaba, e este acontece jogando-se repetidas vezes, para se ganhar experiência, mas também a partir de dicas, macetes e reflexões de outros jogadores, não só sobre o jogo em si mas também sobre o gerenciamento da carreira profissional. Livros, sites e blogs são importantes nesse aspecto, são os espaços de aconselhamento e aprendizagem do jogo de pôquer e do jogo envolvido na administração do dinheiro, no planejamento financeiro, onde o profissional do pôquer imagina-se como investidor de uma empresa de si mesmo.

Já os fóruns são um espaço mais diverso e, de alguma forma, democrático. Além do citado comércio informal de créditos, trata-se de um espaço nivelado de interação entre indivíduos. Sites e revistas, ainda que na internet, têm suas linhas editoriais e propósitos definidos. Blogs são pessoais, têm seus donos, que são os gerentes e as estrelas desses espaços. 
Os fóruns são como praças abertas, onde as pessoas circulam, se mostram e onde há mais abertura temática. Fazer o famigerado networking, recomendação tão comum no mundo do trabalho gerencial, está entre as dicas sobre o que é necessário para tornar-se profissional (11).

Esse mostrar-se, construir um nome e uma reputação nesses espaços informacionais pode ser um atalho para uma carreira profissional de sucesso. Galgar os passos de uma carreira profissional sozinho é possível, mas bastante difícil. O jogador precisa ter ou construir um capital que o permita vencer as instabilidades, a variância inerente ao pôquer, tanto diariamente, administrando seu jogo de maneira cuidadosa e correndo poucos riscos, como no médio e longo prazo, tentando vencer possíveis períodos de vacas magras. Vários relatos dão conta de que o jogador pressionado a pagar as contas do mês tem desempenho pior. Levam vantagem aqueles que conseguem entrar paulatinamente na carreira ou que tenham alguma fonte de renda garantida.

Para quem não tem, os times podem ser uma alternativa. Eles são grupos de jogadores que se reúnem, por si mesmos ou por recrutamento, e compartilham treinamento, compromisso de envolvimento e um fundo mútuo. O chamado bankroll, o dinheiro para jogar, é coletivizado, com regras definidas pelo grupo sobre os pagamentos regulares feitos aos jogadores. Ser convidado a estar em um time envolve confiança e talento demonstrado.

Outra opção, que também envolve contatos feitos principalmente em fóruns de discussão, é a "cavalagem" ou staking. Nela o jogador vende cotas - como uma empresa vende ações -, para um ou mais interessados, com o objetivo de participar de um conjunto de torneios ou para receber dinheiro a ser apostado durante um período de tempo. Depois do tempo combinado ou dos torneios o investidor recebe parte dos lucros, descontando o investimento feito.

\section{TRACKING E A VERIFICAÇÃO COMO CONDIÇÃO PARA O SUCESSO A}

construção de uma imagem de si como "winner", como alguém com habilidades comprovadas e passível de recebimento de investimentos com probabilidade de sucesso, requer tanto uma capacidade pessoal de exibir-se nos espaços adequados como depende da existência de mecanismos de verificação, registro e rastreio do desempenho dos jogadores. Mecanismos que se mostrem, por um lado, globais e, por outro, que sejam confráveis. Alguns sites fazem isso, mostrando o histórico de desempenho dos jogadores e suas perdas e ganhos ao longo do tempo. São grandes bancos de dados mineráveis, que mostram o desempenho de jogadores do mundo todo.

A centralidade na informação, e especialmente nos bancos de dados informacionais, é um dos aspectos que une os sites de pôquer a outras variadas atividades de entretenimento, trabalho e comunicação que ganharam a internet. Os sites disponibilizam históricos das mãos dos jogadores, permitindo o estudo e escrutínio posterior das ações de todos os jogadores. Os investimentos são realizados em grande parte confiando-se nesses dados e traçando-se cenários para o futuro a partir dessas informaçōes.
Além das práticas de mineração há, como nas redes sociais, os mecanismos de software e sociais que levam à auto-exposição dos jogadores. Conseguir entrar numa equipe ou obter financiamento para uma "cavalagem" envolve uma promoção de si nos espaços de interação. Expor os próprios dados em um blog, por exemplo, contando de suas estratégias, histórico positivo e performance ajuda a atrair a atenção. Dar dicas para os iniciantes, ajudar em treinamentos, reunir informações confiáveis contribui para a construção de uma personalidade pública ligada ao pôquer.

Da mesma maneira que as empresas usam celebridades na promoção do jogo, jogadores renomados ajudam a trazer credibilidade para as empresas. Enquanto a Poker Stars, maior empresa do ramo, simbolicamente liga o pôquer a um esporte, centralizando sua promoção na contratação de atletas renomados, empresas menores buscam por jogadores de pôquer famosos, visando inspirar confiança nos jogadores profissionais e significarem-se como espaços especializados e menos amadores.

Nem todos podem ser celebridades, guias, histórias de sucesso. Para haver winners é preciso haver losers, para existirem famosos é preciso que existam os anônimos. Mas é a busca pelo topo, pelo ganho, pela notoriedade, que faz mexer a máquina informacional, que produz vida/dados nas redes e nas mesas de pôquer. Os pequenos ganhos cotidianos são a etapa intermediária imaginária que antecede o momento de entrada na elite, a hora em que o grande patrocínio será fechado ou o que bankroll acumulado será tão grande que jogar será de novo um hobby e não um trabalho. E, por isso mesmo, seria o momento da melhor performance, sem tilt, livre das pressões que prejudicam o melhor jogo.

\section{A MEGA-MÁQUINA INFORMACIONAL}

Os inventores dos computadores são os construtores de pirâmides do nosso tempo: inflados psicologicamente por similar mito de poder sem qualidades, impulsionados por meio de sua ciência em sua crescente onipotência, se não onisciência, movidos por suas obsessões e compulsões não menos irracionais do que aquelas dos primeiros sistemas absolutistas: particularmente a noção de que o sistema em si precisa ser expandido, não importando o eventual custo em vidas (12).

Ao buscar responder à pergunta sobre que tipo de tecnologia humana, tão poderosa, teria sido utilizada pelos antigos egípcios para a construção de algo tão grandioso como as pirâmides, o historiador e sociólogo estadunidense Lewis Mumford chega a uma resposta que, em seu tempo, pode ser considerada longe do trivial. A grande invenção egípcia não teria sido nenhum objeto específico, nenhuma alavanca gigantesca capaz de fazer o trabalho de mil homens. $\mathrm{O}$ que teria possibilitado os esforços dos egípcios seria uma máquina social, uma organização que integrou animais, homens, mulheres, crianças, instituições e, também, equipamentos.

Nesse mesmo sentido, Christopher May argumenta por uma in- 
terpretação da sociedade da informação como uma megamáquina. Apoiando-se em Mumford, May faz uma ponte entre a caracterização da megalópole como megamáquina com uma reflexão sobre a sociedade da informação (12).

A megalópole, em sua forma de cidade invisível, é o claro precursor da sociedade da informação no trabalho de Mumford. Ainda que a terminologia seja diferente, há uma clara correlação entre as oportunidades e os problemas da sociedade da informação. A sociedade da informação, supostamente, permite acesso a partir de todos os lugares (ou ao menos qualquer lugar com rede) aos bens culturais, informacionais e políticos que estão distribuídos pelo sistema. A sociedade da informação como megalópole não tem centro formal mas permite contato imediato com qualquer de suas partes componentes (lembra as origens da internet na amorfa estrutura de comando e controle da Arpanet militar dos Estados Unidos, desenhada para não ter estrutura de comunicação fixa, a permitir o fluxo de informação mesmo se os elementos estivessem "nocauteados"). Já no caso das megalópoles, a sociedade da informação é, ao mesmo tempo, emancipadora e limitadora da experiência humana. Embora os recursos intelectuais estejam agora disponíveis, também há uma centralização de poder, uma crescente capacidade de controle e vigilância. A metrópole mantém seu poder enquanto progressivamente engole outras áreas da atividade humana dando a impressão de ganho de poder individual.” (13).

É preciso levar os jogadores profissionais de pôquer a sério quando eles argumentam pensar sua atividade como um trabalho. Para além de seus pontos de vista individuais e da disciplina auto imposta, eles parecem cumprir uma função no mundo do pôquer de uma maneira geral e para os sites de jogos em particular. Na aventura que empreendem em busca de uma vida melhor-ou mesmo de pagarem as contas do dia a dia -, são como uma peça na megamáquina de geração de informação e de produção de valor. Ou uma das máquinas que se acopla a outras máquinas. Ajudam no entretenimento dos jogadores amadores, que pagam com apostas por esses momentos de diversão. Ensinam o jogo, em seus sites e blogs, e estimulam os aspirantes a profissionais a continuarem jogando - que o fazem para aprender a jogar melhor. São recompensados pelos sites de pôquer se fazem hora extra, se jogam por muitas horas, recompensa que vem em forma de rakeback, os descontos nas taxas de jogo. E tem sua performance rastreada, vigiada, registrada, armazenada e controlada constantemente, como é característico da internet contemporânea.

Mesmo a típica trajetória de sucesso no pôquer guarda relação com as recentes histórias de sucesso e de profissionalização das ocupaçôes criativas na era das redes sociais. Estas se tornaram, por excelência, o espaço onde é preciso estar, se expor, dar amostras de seu trabalho e talento, além de se construir relaçôes, se se deseja sucesso nesse tipo de profissão. Vejamos o seguinte post, retirado da página do Facebook de um popular veículo de informação e entretenimento anunciando a contratação de mais um produtor de conteúdo a integrar a equipe:
O [funcionário] é o novo contratado do [veículo] Brasil e está começando hoje! [funcionário] fará parte do [corruptela do nome do veículo com a palavra team, time em inglês], a parte da redação que escreve posts relacionados a cultura pop, TV, internet e etc.

[funcionário] estava mandando muito bem no Community (dá pra ver os posts antigos dele aqui [URL com username do funcionário enquanto era colaborador voluntário], e nós da redação nos divertíamos muito com ele e os leitores do site também.

Além disso, ele é o criador de algumas das pages mais legais aqui [Facebook] [página de humor 1 e página de humor 2] e é fã de [cantor] (na foto, ele faz o [símbolo do cantor com as mãos]).

Em breve teremos mais anúncios e também novas vagas para a redação. Sempre lembrando que o [URL do veículo que reúne contribuiçōes voluntárias dos leitores] é uma das melhores formas de testar se você curte o [veículo] e da gente conhecer novas pessoas para virem trabalhar conosco.

Entender o mundo do pôquer profissional pode ser importante por si mesmo. Nos ajuda a pensar sobre as mudanças no mundo do trabalho: que atividade profissional é essa que consiste em jogar?; são os pretensos profissionais do pôquer mais comparáveis a peças de uma máquina ou a trabalhadores em uma fábrica?; ou são como empresas, em que se é um gerente de si mesmo, administrando-se como um ativo econômico, em que até a saúde do corpo e a boa vida social (14) são condições desejáveis para um melhor desempenho? $\mathrm{O}$ pôquer também nos dá pistas sobre relações econômicas entre Norte e Sul, como a diferença cambial e no custo de vida entre os países impacta a escolha ou não de uma determinada atividade.

Mas olhar para esse mundo também nos ajuda a entender processos que fazem parte das novas características de circulação do trabalho intelectual em tempos de internet. As redes eletrônicas de relacionamento social se tornaram também o espaço privilegiado de consumo ou de contato com obras culturais e artísticas. É ali que os profissionais divulgam seus trabalhos e a si mesmos, entretendo, informando e, de variadas formas, fazendo networking. As redes se tornaram, quase que necessariamente, um lugar a se estar/produzir/ compartilhar para quem deseja se estabelecer profissionalmente nessas áreas. Mas não é ali que acontecem os possíveis ganhos, nem o mínimo. É preciso estar ali para sair dali, para habitar outros espaços com relações de venda da força de trabalho mais formalizadas.

Já os donos desses espaços, as grandes empresas de tecnologia da informação, encontraram maneiras de fazer dinheiro com essa atividade que passam pelo monitoramento, rastreio e registro eletrônico dos dados trocados entre os usuários, convertendo-os em algo comercializável principalmente em termos publicitários. $\mathrm{O}$ funcionamento da megamáquina informacional é o motor de lucro das empresas, que tem os dados como seu combustível. 
Nem todos e nem tudo o que acontece ali tem propósitos profissionais, a maioria está, como os amadores do pôquer, pela diversão, pela amizade, para matar o tempo. Na verdade, como são de múltiplo propósito, essas redes tornam a divisão dos indivíduos em determinados papéis delimitados totalmente insuficiente. Se é amador e profissional ao mesmo tempo, comediante e cientista, cineasta e poeta, fotógrafo e escritor. Mas, em termos de dados e informações a serem circulados e valorizados, todas essas facetas servem igualmente.

Rafael Evangelista é doutor em antropologia social, pesquisador do Laboratório de Estudos Avançados em Jornalismo (Labjor) e professor do Programa de Pós-Graduação em Divulgação Científica e Cultural da Universidade Estadual de Campinas (Unicamp). Email: rae@unicamp.br

\section{NOTAS E REFERÊNCIAS}

1. Natasha Schull, antropóloga com pesquisa sobre adicção e máquinas de caça-níqueis, relata ter sido procurada por desenvolvedores de aplicativos de celular. Ela compara o "zoning out", a sensação de alheação relatada pelos jogadores de caça-níqueis, com sensação relatada e observada em usuários de jogos de celulares. (ver Annechino, R.. "The addiction algorithm: an interview with Natasha Dow Schüll". Ethnography Matters. Disponível em: <http://ethnographymatters.net/blog/2015/02/09/the-addiction-algorithm/>. Acesso em: 27 out. 2015. Ver também "How do people become addicted to online games and social networking sites?".| MIT School of Engineering. Disponível em: <http://engineering.mit.edu/ask/how-do-people-become-addicted-online-games-and-social-networking-sites〉. Acesso em: 27 out. 2015.)

2. McCormack, A.; Griffiths, M. D. “What differentiates professional poker players from recreational poker players? A qualitative interview study". International Journal of Mental Health and Addiction, v. 10, n. 2, p. 243-257, 2012.

3. The online game market. Disponível em: <https://www.bwinparty. com/AboutUs/OurMarkets/The\%20online\%20gaming\%20market. aspx>. Acesso em: 27 out. 2015.

4. Playing poker professionally | Life of an online poker player. Disponível em: 〈http://www.rakemonkey.com/playing-poker-for-a-living〉. Acesso em: 27 out. 2015.

5. O Rakemonkey é um site especializado em informações sobre bônus e descontos para jogadores online frequentes.

6. Akkari, A.; [Artigo] André Akkari - "Lucratividade no poker". Disponível em: <http://www.buildagrinder.com/bgcom/index.php?option=com_kunena\&func $=$ view\&catid=103\&id $=1555 \&$ lang $=$ br\&ltemid $>$. Acesso em: 27 out. 2015.

7. Begara, V. "Re-post" - Jogando por times e por conta própria! SuperPoker. Disponível em: 〈http://www.superpoker.com.br/blog/headao/re-post-jogando-por-times-e-por-conta-propria->. Acesso em: 27 out. 2015.

8. Bello, L. "Dominando a arte do poker: profissional vs. amador CardPlayerBrasil.com". Disponível em: <http://www.cardplayer- brasil.com/site/revistas_ver2.asp?ed=27\&cod=420>. Acesso em: 27 out. 2015.

9. Dance, G. "Poker bots invade online gambling". The New York Times, 2011. Disponível em: <http://www.nytimes.com/2011/03/14/science/14poker.html>. Acesso em: 27 out. 2015.

10. Wood, R. T. A.; Griffiths, M. D. “'Why swedish people play online poker and factors that can increase or decrease trust in poker web sites: a qualitative investigation". Journal of Gambling Issues, p. 80-97, 2008.

11. Bello, L. op. cit.

12. Lewis Mumford apud May. No original em inglês: "The inventors of ... computers are the pyramid builders of our own age: psychologically inflated by a similar myth of unqualified power, boasting through their science of their increasing omnipotence, if not omniscience, moved by obsessions and compulsions no less irrational than those of earlier absolute systems: particularly the notion that system itself must be expanded, at whatever eventual cost to life". (Mumford 1964: 5) apud May.

13. May, 2000, p.256. No original em inglês: “The megalopolis in its form of the invisible city is the clearest precursor to the information society within Mumford's work. Though the terminology is different, there is a clear correlation with the opportunities and problems of the information society. The information society, it is supposed, allows access from anywhere (or at least anywhere within the network) to the cultural, informational and political assets that are distributed throughout the system. The information society as megalopolis has no formal centre but enables immediate contact with any of its component parts (recall the origins of the Internet in the amorphous command and control structure of the US military's Arpanet, designed to have no fixed structure of communication, to allow information to flow even if elements were 'knocked out'). As with the megalopolis, the information society is both empowering and limiting of human experience. Though intellectual resources are now available, there is also a centralization of power, an increased capacity for control and surveillance. The metropole retains its power while progressively swallowing up other areas of human activity and giving an impression of individual empowerment." May, C. op. cit.

14. "( ) quem quer entrar de cara nessa carreira, precisa, antes de saber jogar poker, ter uma vida estável, ter uma "base" para segurar nos primeiros meses, que provavelmente serão duros. Ter amigos "off poker" para se manter no "mundo real (...), procurar um novo hobby também é muito importante, já que agora o hobby poker vai passar a ser uma profissão, e por mais que você ame isso tudo, é muito diferente você jogar $10 \mathrm{~h}$ por dia do que jogar 5 ou $6 \mathrm{~h}$ por semana, nós sempre precisamos estar fazendo algo que nos agrade que não esteja relacionado ao nosso trabalho. Tendo tudo isso a "vida útil" do jogador vai ser muito maior, o tesão no trabalho vai ser maior e consequentemente o desempenho será muito melhor". Begara, V. op. cit. 